\title{
ANÁLISE DA INFLUÊNCIA CLIMÁTICA NA VEGETAÇÃO E NA AGROPECUÁRIA DA REGIÃO NORDESTE DA BAHIA
}

\author{
$\underline{\text { Natália de Brito Lima }}{ }^{1}$; Hermilino Danilo Santana de Carvalho²; Elane Fiuza \\ Borges $^{3}$ \\ 1.Bolsista PROBIC, Graduanda em Bacharelado em Geografia, Universidade Estadual de Feira de Santana, e-mail: \\ natilima97@gmail.com \\ 2. Orientador, Departamento de Ciências Humanas e Filosofia, Universidade Estadual de Feira de Santana, e-mail: \\ hdscaralho@gmail.com \\ 3. Orientador, Departamento de Ciências Humanas e Filosofia, Universidade Estadual de Feira de Santana, e-mail: \\ elaneborges@gmail.com
}

PALAVRAS-CHAVE: EVI; produção agrícola; influência climática.

\section{INTRODUÇÃO:}

No semiárido brasileiro, a desertificação é um dos mais graves problemas socioambientais. Na Bahia, as áreas susceptíveis à desertificação são definidas como polos regionais, que são: pólo de Guanambi, pólo de Irecê, pólo de Jeremoabo e pólo de Juazeiro. Estudo realizado por Lobão (2010) aponta que o pólo de Jeremoabo, localizado no nordeste da Bahia (composto pelos municípios de Canudos, Uauá, Macururé, Rodelas, Chorrochó, Paulo Afonso, Glória, Santa Brígida, Pedro Alexandre, Coronel João de Sá, Novo Trunfo, Antas e Jeremoabo) é o mais vulnerável a desertificação no estado da Bahia, gerando assim, graves problemas socioambientais.

A região semiárida sofre bastante influência das condições climáticas na sua formação vegetal, uma vez que, nesta região, predomina o bioma da caatinga, onde os diferentes tipos vegetacionais resultam da integração clima-solo (ANDRADE-LIMA, 1981) por conta do clímax climático, quando o clima condiciona o tipo de vegetação presente em determinada área (IBGE, 2012). Uma vez que os fatores climáticos influenciam na vegetação, consequentemente, também influenciará na produção agrícola. Mesmo com todos os recentes avanços tecnológicos e científicos, o clima ainda é a variável mais importante para a produção agrícola. Os principais elementos climáticos que afetam a produção agrícola são os mesmos que influenciam a vegetação natural. Entre eles se incluem a radiação solar, a temperatura e a umidade (AYOADE, 2010).

A cobertura vegetal pode ser uma das variáveis da paisagem considerada mais dinâmica, haja vista que esta é bastante vulnerável à ação dos fenômenos climáticos, ao fogo e à ação antrópica, de modo geral (BORGES, 2014). Desta forma, para que haja um monitoramento eficiente da vegetação, faz-se necessário o uso das Geotecnologias, em particular o Sensoriamento Remoto, que foi a principal ferramenta aqui utilizada.

\section{MATERIAL E MÉTODOS:}

Neste estudo, foram destacados dois municípios, Uauá e Paulo Afonso, que fazem parte do pólo Regional de Jeremoabo, localizados no nordeste do estado da Bahia (figura 1).

Figura 1 - Mapa de localização dos municípios de Paulo Afonso e Uauá.

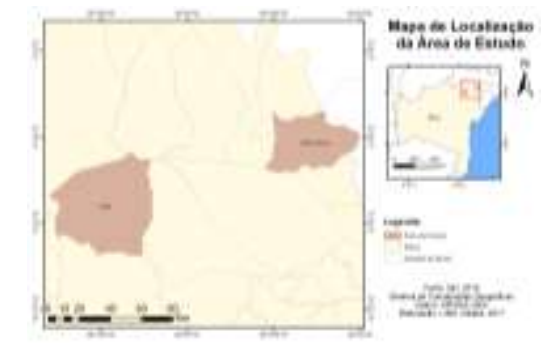


Eles inserem-se na Área Suscetível à Desertificação e há indicativos de altos níveis de degradação ambiental (VALE; LOBÃO, 2013; OLIVEIRA JUNIOR, 2014). O domínio climático é o tropical semiárido, com precipitações pluviométricas concentradas e irregulares, com anos de vazios de chuvas, o que caracteriza o fenômeno da seca, e o índice de aridez é acentuado. Os municípios encontram-se situados no bioma Caatinga, a feição vegetal predominante é a caatinga arbórea-arbustiva e as principais atividades socioeconômicas decorrentes, em extensão territorial, é a agropecuária (OLIVEIRA JUNIOR, 2014).

Optou-se por trabalhar com apenas dois municípios, Uauá e Paulo Afonso, que fazem parte do pólo Regional de Jeremoabo, uma vez que esses dois municípios, mesmo próximos, demonstraram certa disparidade nos seus índices pluviométricos. Já no que diz respeito ao recorte temporal, foram escolhidos também dois anos. Um ano que comparado aos outros analisados, teve um percentual considerado alto de precipitação pluviométrica, que foi 2010 e um ano onde foi de seca hídrica em todo o Nordeste brasileiro, que foi 2012.

Em paralelo, foram reunidos e tabulados dados do IBGE referentes à produtividade agrícola dos municípios componentes da área de estudo (Paulo Afonso e Uauá). Para a análise do comportamento da biomassa, foi empregado o Enhanced Vegetation Index (EVI):

$$
E V I=G^{*} \frac{I V P-V}{I V P+C_{1}{ }^{*} V-C_{2}{ }^{*} A+L}
$$

onde $\mathrm{IVP}=$ reflectância no infravermelho próximo; $\mathrm{V}=$ reflectância no vermelho; $\mathrm{A}=$ reflectância no azul; $\mathrm{C}_{1}=$ coeficiente de correção dos efeitos atmosféricos para a banda do vermelho (6); $\mathrm{C}_{2}=$ coeficiente de correção dos efeitos atmosféricos para a banda do azul $(7,5)$; $\mathrm{L}=$ fator de correção para a interferência do solo (1); $\mathrm{G}=$ fator de ganho $(2,5)$. $\mathrm{O}$ índice foi escolhido pois tem mostrado bastante eficácia no monitoramento agrícola. Este índice utiliza informações na região espectral do infravermelho próximo, região do vermelho e a reflectância na faixa do azul para indicar o vigor vegetativo dos biomas. Para tal, obteve-se imagens do sensor MODIS, acoplado ao Satélite Terra, produto MOD13Q1, no formato TIFF, produzidas a partir da composição de 16 dias, com resolução espacial de $250 \mathrm{~m}$. Foram utilizadas ao total 46 imagens, imagens essas extraídas do banco de dado da Embrapa (Banco de Produtos MODIS). Em seguida todos estes dados foram integrados e analisados.

\section{ANÁLISE E DISCUSSÃO DOS RESULTADOS:}

A diferença hídrica entre os anos de 2010 e 2012 foi muito representativa nos municípios aqui trabalhados, inclusive no município de Uauá (figura 2), que teve uma queda em mais de $100 \%$ do seu total pluviométrico anual em 2010 se comparado a 2012. Isto ocorreu por conta da seca hídrica que ocorreu em todo o nordeste brasileiro.

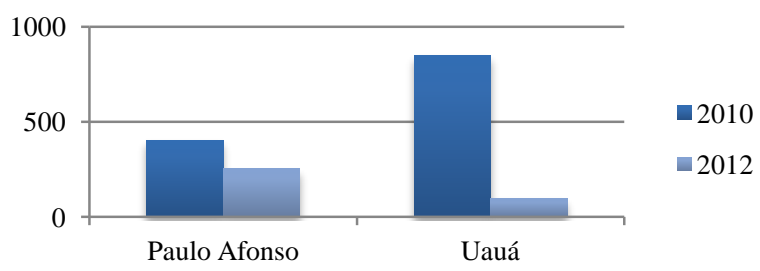

Figura 2 - Diferença pluviométrica nos municípios de Paulo Afonso e Uauá nos anos de 2010 e 2012.

No ano de 2010, no município de Paulo Afonso o total hídrico foi de $404 \mathrm{~mm}$, comparado com Uauá, que no mesmo ano teve um total de $849,4 \mathrm{~mm}$, considerado alto para o seu domínio climático. Já no ano de 2012, essa quantia hídrica caiu bastante. Em Paulo Afonso a queda na precipitação pluviométrica foi bastante expressiva, porém o impacto no déficit hídrico foi mais significativo em Uauá. 
No município de Paulo Afonso, de acordo com os dados disponibilizados pelo Instituto Brasileiro de Geografia e Estatística (IBGE), no ano de 2010 a lavoura temporária teve uma boa produtividade (6.670 toneladas), se comparado com o ano de 2012 (703 toneladas) que para alguns dos produtos agrícolas cultivados no município não foram encontrados registros. Já na lavoura permanente, houve uma pequena queda, nada tão significativo quanto na lavoura temporária, mas teve. Em 2010 teve um total de 715 toneladas e em 2012 a produtividade permanente apresentou um total de 707 toneladas.

No município de Uauá, os danos na produção agrícola em decorrência da seca foram ainda mais acentuados que em Paulo Afonso, tendo uma queda quase que absoluta tanto na sua lavoura temporária quanto na permanente. No ano de 2010 o município produziu uma lavoura permanente que equivaleu a 7.762 toneladas, maior que a de Paulo Afonso. Já em 2012, não foram encontrados registros para a maioria dos produtos, tendo apenas o total de área plantada, sem colheita. Até a sua lavoura permanente, que já não é muito forte no município, pelo menos no recorte temporal aqui estabelecido, caiu totalmente. Em 2010 o município obteve uma produção agrícola equivalente a 660 toneladas, já em 2012 esse total foi de apenas 20 toneladas.

A queda da precipitação pluviométrica não acarretou somente na diminuição da produção agrícola, mas também na biomassa vegetal da área de estudo, como pode ser verificado nas figuras abaixo:

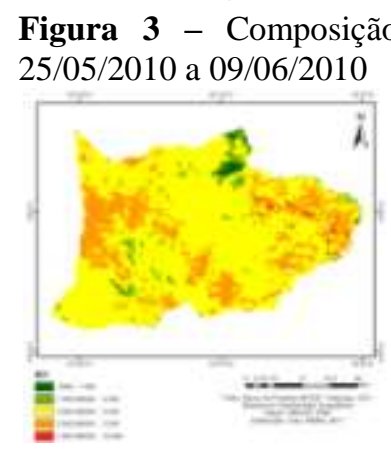

Figura 7 - Composição 25/05/2010 a 09/06/2010

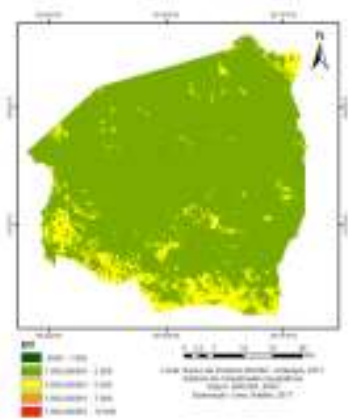

Figura 4 - Composição 24/05/2012 a 08/06/2012

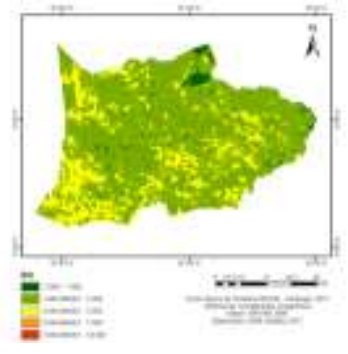

Figura 8 - Composição 24/05/2012 a 08/06/2012

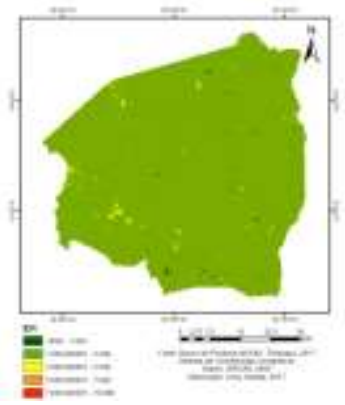

Figura 5 - Composição 03/12/2010 a $18 / 12 / 2010$

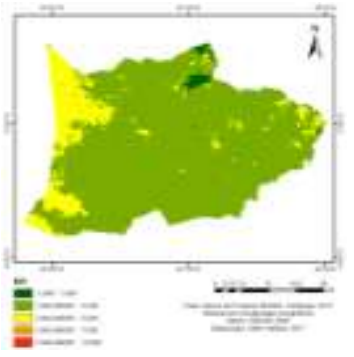

Figura 9 - Composição 03/12/2010 a 18/12/2010

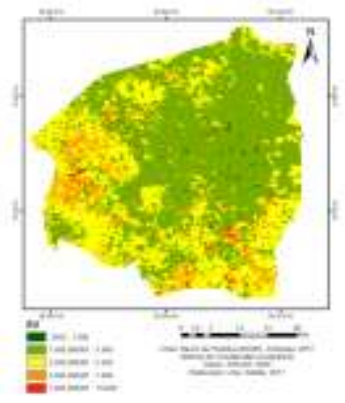

Figura 6 - Composição $02 / 12 / 2012$ a $17 / 12 / 2012$

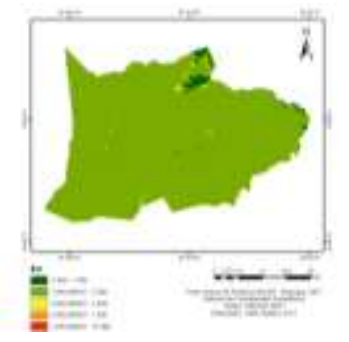

Figura 10 - Composição 02/12/2012 a 17/12/2012

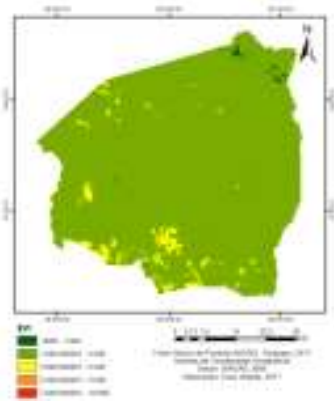

Fazendo-se um comparativo entre os mesmos períodos de composições de EVI, nos diferentes anos, nos dois municípios que compreendem a área de estudo, podemos observar como a presença de biomassa vegetal é bem menos representativa para o ano de 2012, como averiguado nas figuras. No ano de 2010, o EVI mais representativo foi na composição do período do outono (figura 3). Em 2012 (figura 4), na mesma estação, tivemos a presença na maioria da extensão territorial do município da segunda classe (entre 1.000.000001 e 3.000), que é considerado baixo EVI. 
A primavera foi a estação onde pudemos observar os menores índices de vegetação melhorada para os dois anos trabalhados, e para os dois municípios (figuras 3 a 10) porém, em 2012 temos em sua maioria apenas a presença das primeira e segunda classes, o que significa que em quase a extensão dos municípios temos quase que a ausência de biomassa vegetal. Em 2010 também caiu bastante o índice. No extremo norte de Paulo Afonso, constatamos em todas as composições de EVI, a presença de uma pequena extensão representada pela primeira classe, que é onde fica localizado o lago do Sobradinho, significa que nessa extensão temos a ausência total de biomassa. Em Uauá a queda do índice da biomassa vegetal foi ainda mais perceptível que em Paulo Afonso, mas em ambos no ano de 2012 tiveram uma grande queda.

\section{CONSIDERAÇÕES FINAIS:}

Com o desenvolvimento da presente pesquisa, foi possível concluir que a produção agrícola dos municípios de Paulo Afonso e Uauá acompanhou a precipitação pluviométrica nos dois anos trabalhados. Em 2010 teve-se uma boa precipitação pluviométrica, o que acarretou no bom desempenho da produção agrícola municipal, que teve um índice muito alto. Já no ano de 2012, a precipitação teve uma queda bastante expressiva e, consequentemente, a produção agrícola também teve um grande déficit. Sendo assim, em anos de seca hídrica, podemos esperar juntamente um declínio na produção agrícola. O EVI se mostrou bastante eficiente na elaboração do trabalho. Uma vez que, com a queda pluviométrica e da produção agrícola, pudemos identificar, também, a queda da biomassa vegetal apresentada pelo EVI.

\section{REFERÊNCIAS:}

ANDRADRE-LIMA, D. de. 1981. The caatingas dominium. Revista Brasileira Botânica 4:149-53.

AYOADE, J. O. Introdução à climatologia para os trópicos. $6^{\mathrm{a}}$ edição. - Rio de Janeiro: Bertrand Brasil, 2010.

BORGES, E. F. Discriminação e caracterização fenológica de classes de cobertura vegetal natural e antrópica do Oeste da Bahia a partir de séries temporais do sensor Modis. 2014. 138 f. Tese (Doutorado em Geociências Aplicadas). Universidade de Brasília. Brasília, 2014.

BRASIL - INSTITUTO BRASILEIRO DE GEOGRAFIA E ESTATÍSTICA. Manual técnico da vegetação brasileira. IBGE: Rio de Janeiro, 2012.

GUSSO, Anibal et al. Aplicação de séries temporais EVI/MODIS na identificação do uso e ocupação do solo anterior ao cultivo da cana-de-açúcar In: Anais XIV Simpósio Brasileiro de Sensoriamento Remoto, 2009. Natal, Brasi. INPE, p. 5851-5856.

LOBÃO, J. S. B. Análise socioambiental na região semiárida da Bahia: geoprocessamento como subsídio ao ordenamento territorial. Tese (Doutorado em Geografia) Programa de Pós-Graduação em Geografia, Universidade Federal de Sergipe, 2010.

-----, J. S. B.; VALE, R. M. C. Lógica Fuzzy na modelagem da desertificação no estado da Bahia. Geografia, Rio Claro. v. 38, n. 1, p. 123-140, 2013.

OLIVEIRA JUNIOR, I. O processo de desertificação: a vulnerabilidade e a degradação ambiental no polo regional de Jeremoabo-Bahia. Dissertação (Mestrado em Geografia) Programa de Pós-Graduação em Geografia, Universidade Federal da Bahia, Instituto de Geociências, Salvador, 2014. 